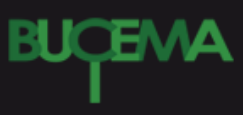

Bulletin du centre d'études médiévales d'Auxerre | BUCEMA

13 | 2009

Varia

\title{
La « salle opérationnelle » de l'ancien palais épiscopal (préfecture) d'Auxerre (Yonne)
}

\section{Vanessa Hontcharenko}

\section{(2) OpenEdition}

1 Journals

Édition électronique

URL : https://journals.openedition.org/cem/11162

DOI : 10.4000/cem. 11162

ISSN : 1954-3093

Éditeur

Centre d'études médiévales Saint-Germain d'Auxerre

\section{Édition imprimée}

Date de publication : 15 août 2009

Pagination : 13-17

ISSN : 1623-5770

\section{Référence électronique}

Vanessa Hontcharenko, «La « salle opérationnelle » de l'ancien palais épiscopal (préfecture) d'Auxerre (Yonne) », Bulletin du centre d'études médiévales d'Auxerre | BUCEMA [En ligne], 13 | 2009, mis en ligne le 18 septembre 2009, consulté le 22 septembre 2022. URL : http://journals.openedition.org/cem/11162 ; DOI : https://doi.org/10.4000/cem.11162

Ce document a été généré automatiquement le 22 septembre 2022.

\section{(c) (i) (8)}

Creative Commons - Attribution - Pas d'Utilisation Commerciale - Partage dans les Mêmes Conditions 4.0 International - CC BY-NC-SA 4.0

https://creativecommons.org/licenses/by-nc-sa/4.0/ 


\title{
La « salle opérationnelle » de l'ancien palais épiscopal (préfecture) d'Auxerre (Yonne)
}

\author{
Vanessa Hontcharenko
}

1 Les travaux d'aménagement d'une salle opérationnelle dans les locaux de la Préfecture de l'Yonne ont permis de mettre au jour des éléments parfaitement conservés du palais épiscopal d'Auxerre, datant du deuxième quart du XII ${ }^{\mathrm{e}}$ siècle. Située sous le promenoir édifié sous l'épiscopat d'Hugues de Montaigu (1114-1136), la salle dégagée préserve les élévations originelles d'un palais construit suite à un incendie ayant ravagé le quartier épiscopal au cours du $\mathrm{XI}^{\mathrm{e}}$ siècle. Les deux interventions archéologiques de terrain, en juin et en août 2008, ont eu pour objectif de définir l'aspect architectural de cette salle et sa fonctionnalité, de comprendre l'organisation interne de l'édifice et d'en déterminer son évolution. La réalisation d'un corpus de plans et de relevés illustre ce patrimoine exceptionnel. La structure originelle, très homogène, témoigne de l'exécution romane. Les interventions ultérieures ont adapté la salle à de nouvelles exigences fonctionnelles sans modifier l'ossature de l'édifice qui demeure très lisible.

2 Le palais d'Hugues de Montaigu, appuyé partiellement sur la fondation d'une habitation antérieure ou d'un mur de terrasse palliant la déclivité du terrain, se situe au nord-est de la cathédrale Saint-Étienne, sur le flanc oriental de la cité antique surplombant l'Yonne. La salle concernée par l'étude respecte les proportions de l'ancienne salle romane. L'appareil réglé est constitué de mœllons calcaires. Les chaînes et les ébrasements sont composés de pierres de taille layées préservant les tracés préparatoires et les signatures des tâcherons. La salle romane possédait un faible éclairage fourni par d'étroites baies plein cintre. L'une d'elles subsiste au sud-est. Le mur ouest est rythmé par de larges arcades élancées recevant la portée du mur de refend tout en ouvrant sur d'autres travées, offrant un espace aux vastes proportions. $\mathrm{Au}$ sud-ouest de la salle, une porte à fermeture intérieure flanquée d'une baie étroite avec barreau offrait un accès secondaire, privé ou de service ; l'accès actuel, au nord, est d'une facture moderne. L'entrée principale primitive se situerait au nord de la pièce 
adjacente, actuelle cuisine du Conseil général, dont la voûte est largement reprise à la fin du XVIII ${ }^{\mathrm{e}}$ siècle.

Un plancher parfaitement conservé recouvre l'intégralité de la salle. Il est composé de planches de chêne débitées par fendage tangentiel, reposant sur des solives de brin d'une section moyenne $(30 \times 30 \mathrm{~cm})$. Le poids de cet ensemble est reporté sur les murs porteurs de l'édifice via des lambourdes biseautées supportées par des corbeaux en pierres de taille layées. Aucune fixation n'est utilisée ; le plancher se maintient par le poids de son assemblage et par la portée des maçonneries supérieures. Les analyses dendrochronologiques de Christine Locatelli et de Didier Pousset ${ }^{1}$ renvoient à l'abattage des bois durant l'automne hiver 1125-1126, ce qui confirme les événements rapportés dans les Gesta Pontificum Autissiodorensium ${ }^{2}$. La rareté des témoins de ce type pour la période romane place le plancher d'Auxerre comme référence dans la connaissance des techniques du bois, du point de vue de l'assemblage et, d'une manière plus générale, de celui de l'intégration dans un ensemble architectural.

4 Aménagées dans le mur sud de la salle, deux niches plein cintres géminées à fermetures coulissantes ouvrent sur des conduits inclinés apparentés à un système de vide-ordures double, qui accèdent à une salle voûtée en contrebas. Cette dernière reçoit également le conduit de latrines de l'étage supérieur. La citerne présente une légère inclinaison vers l'est et se réduit en un égout dirigé vers l'Yonne, désormais condamné. Un canal étroit débouchant en amont de la citerne témoigne d'un vaste système récurable d'évacuation des déchets s'étendant à l'ouest, ce qui introduit la question de la gestion de l'eau à Auxerre. La notion d'hygiène semble pleinement intégrée au programme architectural en milieu urbain dès les débuts du XII ${ }^{\mathrm{e}}$ siècle.

5 L'emplacement de la salle à un niveau semi-enterré pose la question quant à sa fonctionnalité. L'absence de toute décoration sculptée ou peinte confère une extrême sobriété à l'espace accentuée par le sol originel en terre argileuse mis au jour dans le sondage. Pourtant les éléments architecturaux observés, notamment le dispositif d'évacuation des déchets, évoquent une vaste pièce fonctionnelle qui n'est pas sans rappeler un réfectoire, et ce malgré sa position inférieure dans la construction.

6 Les premiers remaniements s'observent dès le XIII ${ }^{\mathrm{e}}$ siècle avec la restauration des piles ouest et l'agrandissement des baies orientales dû à la nécessité d'accroître l'apport de lumière. Cependant, seuls les cloisonnements des $\mathrm{XV}^{\mathrm{e}}-\mathrm{XVI}^{\mathrm{e}}$ siècles dénoncent clairement un nouvel emploi de la salle. Les arcades sont bouchées et le vide-ordures condamné. Des marques de comptabilité sont gravées sur les murs. Les résidus de céréales comblant les interstices de l'appareillage évoquent la transformation en un lieu de stockage de foin, de bois et de fruits, confirmée par un inventaire de 1595. Cette fonction demeure jusqu'à la fin du XVIII ${ }^{\mathrm{e}}$ siècle. Les travaux modernes ont alors consisté à réparer les élévations et à aménager des locaux d'habitation. D'une manière générale, les travaux effectués aux époques suivantes sur cette salle du palais d'Hugues de Montaigu n'ont pas détruit les maçonneries d'origine mais le complètent. L'intégralité du palais roman pourrait ainsi être préservée, simplement masquée par les revêtements ultérieurs. L'étude de ces murs, à l'occasion de travaux dans la préfecture de 
l'Yonne, est primordiale pour l'enrichissement de l'histoire des techniques locales de construction adoptées dans un cadre privé très prestigieux.

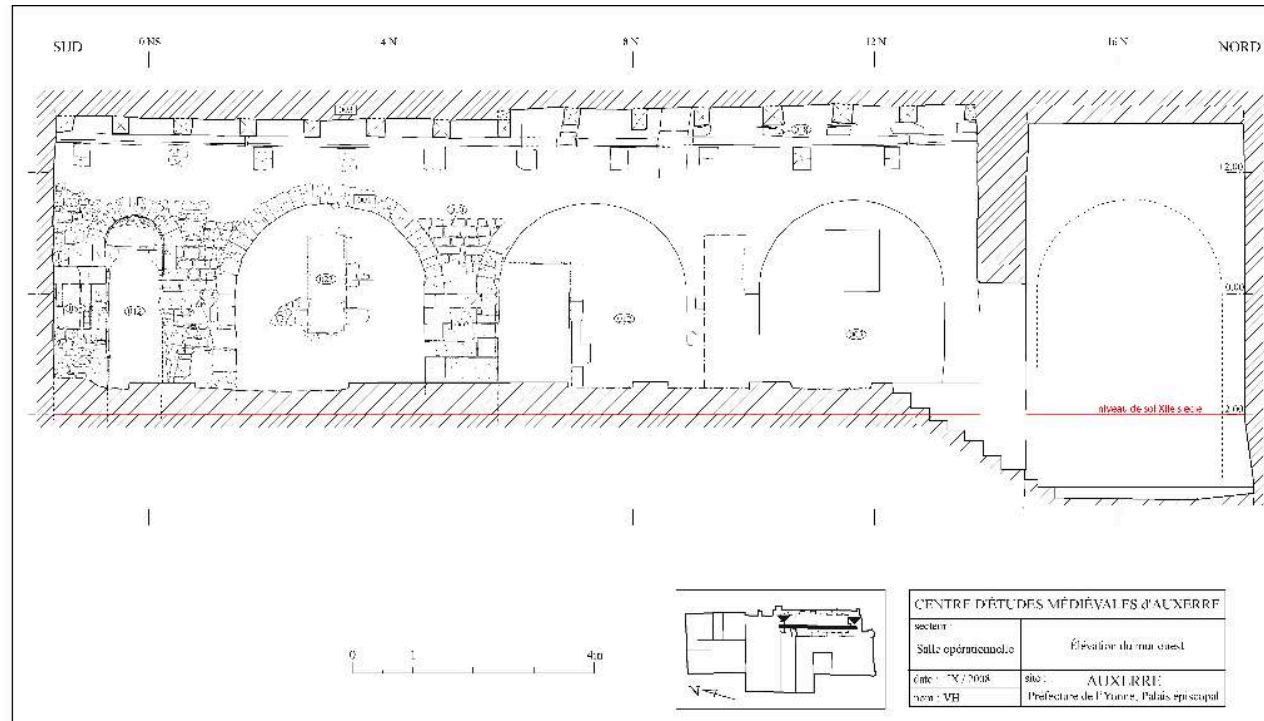

Fig. 1 - Préfecture de I'Yonne, salle opérationnelle, mur ouest (CEM, V. Hontcharenko).

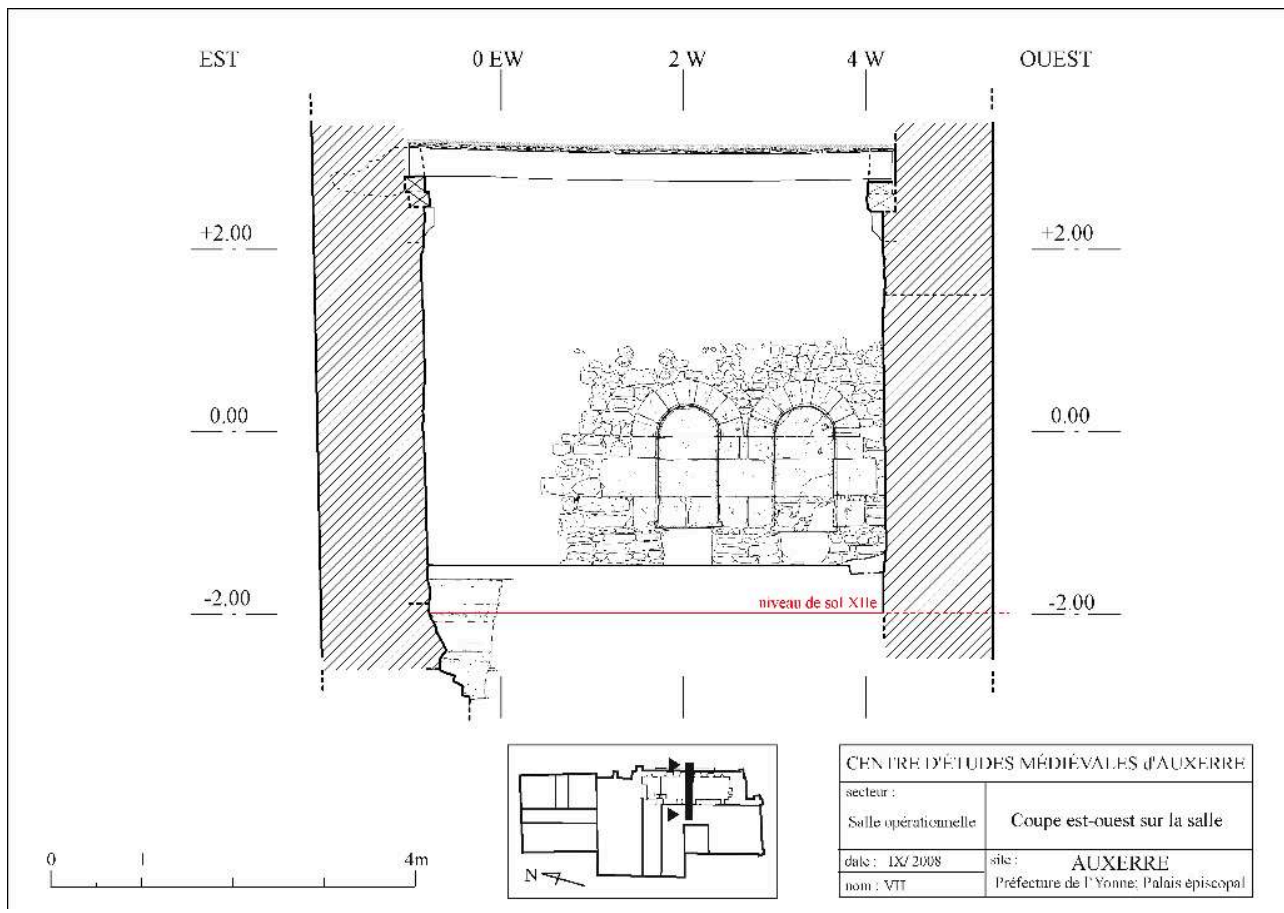

Fig. 2 - Préfecture de I'Yonne, salle opérationnelle, mur sud (CEM, V. Hontcharenko). 
NOTES

1. Dendrochronolgy Consulting, Rapport d'analyse dendrochronologique de la salle opérationnelle de la Préfecture de l'Yonne, septembre 2008.

2. Les Gestes des évêques d'Auxerre, M. SOT dir., 2 vol., Paris, 2002 et 2006.

INDEX

Index géographique : France/Auxerre

Mots-clés : palais épiscopal, préfecture 